\title{
Decline of response rate during signaled deferment of ESB reinforcement
}

\author{
HARRY M. B. HURWITZ \\ University of Guelph, Guelph, Ontario, Canada N1G 2WI \\ and \\ ROBERT E. JAMES \\ University of Alabama, Huntsville, Alabama 35805
}

\begin{abstract}
Five rats with electrodes chronically implanted in the medial forebrain bundle were tested for rates of self-stimulation under signaled and unsignaled deferments of reinforcement. Deferments of 0-5.0 sec between the leverpress and the reinforcement were investigated. The results demonstrate a lower response and reinforcement rate under the signaled procedure. The lower response rate under the signaled procedure may be a function of competing superstitious behaviors or disruptive signal properties that overshadow the reinforcing effects of electrical stimulation of the brain.
\end{abstract}

It has been found in a variety of experimental tasks that the performance of a well-learned response deteriorates when a temporal delay is imposed between the response and its reinforcing consequence. A delay of reinforcement is also associated with a slower rate of conditioning provided one assesses rate of conditioning by measures like latency of response to a stimulus, rate of eliminating alternatives, etc.; if resistance to experimental extinction is used to measure the strength of conditioning, a delay of reinforcement usually results in the verdict that the temporal delay is conducive to a relatively strong conditioned response (Renner, 1964).

A delay between a response and its programmed consequence may, however, take two forms. In the traditional method, the interval between the performance of the response and its consequence is protected in the sense that the subject is prevented from making additional responses of the same class although unrelated responses are permitted. A method devised by the present authors leaves the subject free to make additional responses of the same class. To distinguish the two methods, the term deferment procedure has been assigned to the latter case, which is a modification of a continuous (FR1) free operant reinforcement procedure. The procedure requires that the constant $t$ which is normally set at 0 (a hypothetical value, since there is usually some delay between a response and its consequences) be given the status of a variable. An experiment by Hurwitz and James (1970) demonstrated that the rate of response is dramatically affected by imposing deferment intervals ranging from .5 to $15 \mathrm{sec}$ between

This study was supported by USPHS Grant MH 12115-04 to H. M. B. Hurwitz. Reprints may be obtained from H. M. B. Hurwitz, Department of Psychology, University of Guelph, Guelph, Ontario, Canada N1G 2W1. the response and delivery of an intracranially administered electrical stimulation of the brain (ESB). Because the introduction of a temporal interval between a response and its consequence also changes the density function of the reinforcer, the appropriate control condition is a fixed-interval schedule (FI) which permits one to space the reinforcers but which ensures that the reinforcement following a response is immediate rather than deferred. The experiment showed that there was a substantial response rate differential between deferment and the fixed-interval procedures over all temporal values examined. Indeed, whereas FI schedules maintained the response at some strength, it seemed as if every minute tampering with the response-ESB interval destroyed the basis of the leverpressing behavior of the rat subjects.

The present experiment investigated the possibility that the decline in response rate of an ESB-reinforced response under a deferment procedure could be attenuated by introducing a signal between the response and delivery of ESB. It was reasoned that because the signal would invariably precede ESB, it would acquire some of the response-reinforcing properties of ESB and that, furthermore, it closed an information gap between the subject's behavior and important and distinctive happenings in the environment. There was also some evidence available that rats preferred signaled to unsignaled deliveries of ESB when tested in a shuttlebox situation (Cantor \& LoLordo, 1970). In addition, Cantor (1971) demonstrated that if a single ESB is made predictable by preceding it with a brief exteroceptive warning signal, the establishment and maintenance of operant behavior under schedules of intermittent reinforcement is facilitated. But against this prediction that a signal has response rate preserving functions must be set the 
alternative that the signal reduces rather than enhances response rate. It could be argued that the availability of a signal which indicates the delivery of ESB makes it unnecessary for the subject to perform further responses during the interval, so that rate of response would not necessarily be preserved; rather, the rate of ESB would be maintained at a lower level than in the absence of such a signal. In other words, it is conceivable that the rate of response deteriorates at a faster rate than the rate of delivered reinforcements under FI procedure: Such a result would merely show that the subject's discrimination had improved, whether through its improved judgment of time or through the use of available, distinct exteroceptive cues.

In the present experiment the rate of response and the rate of intracranially delivered ESB were compared under a signaled and unsignaled deferment procedure. Each subject served under all conditions. Temporal intervals of $.5,1.0,2.5$, and $5.0 \mathrm{sec}$ were used to program the deferment interval.

\section{METHOD}

\section{Subjects}

The subjects were five male hooded rats (before implantation they weighed 200-250 g) of the Long-Evans strain obtained from Blue Spruce Farms, New Jersey. Food and water were freely available at all times in the individual home cages of the subjects.

\section{Surgery}

Electrode implantation was performed 2 weeks prior to the beginning of experimental testing. Each animal was implanted under sodium pentobarbital anesthesia $\left(1.0 \mathrm{~cm}^{3} / \mathrm{kg}\right.$ of $48 \mathrm{mg} / \mathrm{kg}$ Nembutal) on a Kopf small-animal stereotaxic instrument with bipolar, stainless steel electrodes (Plastic Products, Roanoke, Virginia). Electrodes were insulated except at the tip and were aimed at the medial forebrain bundle $(1.7 \mathrm{~mm}$ lateral to bregma, $1.5 \mathrm{~mm}$ posterior to bregma, and inserted to a depth of $8.5 \mathrm{~mm}$ below the surface of the skull). After surgery all animals were given $.25 \mathrm{~cm}^{3}$ of $3,000,000 \mathrm{IU} / \mathrm{cm}^{3}$ of procaine penicillin.

\section{Apparatus}

The subjects were run in a sound-attenuated experimental chamber containing one permanent lever programmed to deliver ESB from a 60-cycle stimulator by means of a simplified overhead cable swivel (Cooper, Morse, Potts, \& Black, 1969). The ESB consisted of a biphasic square wave in which each pulse train was of .3-sec duration. The current level (40-100 microA) was independently set for each subject at a level that produced sustained performance under continuous reinforcement. The signal was produced by a Guardian relay heavily dampened with cotton and pulsed at a rate of 5 times $/ \mathrm{sec}$, producing an $85-\mathrm{dB}$ noise. The apparatus was programmed by conventional electromechanical devices, relays, timers, and steppers.

\section{Procedure}

During the first four daily sessions, all subjects were shaped to leverpress under a procedure that made the brain stimulus available immediately upon the press of the lever. The subjects were also accustomed to being in the apparatus during $30-\mathrm{sec}$ time-out periods. During such 30 -sec time-out periods, the lever remained in the apparatus, but the chamber light was extinguished.

Each experimental session from the fifth day onward consisted of 114 -min periods during which pressing the lever would deliver ESBs that were separated by 1030 -sec time-out periods. Thus, the total length of each daily session was 49 min. Periods 1,6 , and 11 were always run under continuous reinforcement (FR1), that is, under a 0 -sec deferment condition. Periods 2-5 and 7-10 were randomly assigned to specified deferment intervals. Deferment intervals of $.5,1.0,2.5$, and $5.0 \mathrm{sec}$ were used. All signaled conditions and all unsignaled conditions were grouped into four consecutive 4-min periods. Signaled and unsignaled conditions were alternated each day, so that Trials 2-5 were signaled one day and Trials 7-10 the next. Each subject served as its own control with respect to the effect of the signal on performance rate.

The deferment interval was timed from the lever release to the delivery of the ESB pulse train. Additional responses made during this interval had no effect on delivery of ESB. Under the signaled condition, the buzzer began when the lever was released and continued to sound for the length of the deferment interval. It terminated with the delivery of ESB.

Each animal was run daily so that approximately $23 \mathrm{~h}$ separated each experimental session. All animals were run a minimum of 6 consecutive days or until it was determined that behavior was stable (6-16 days).

\section{Histology}

Upon termination of the experiment, the rats were given an overdose of sodium pentobarbital and were perfused with $10 \%$ formalin. Brains were removed and stored in formalin; subsequently, frozen sections of $\mathbf{4 0}$ microns stained with cresyl violet were studied to determine the location of the electrode tip. Histological examination showed that all electrode tips were located in the medial forebrain bundle.

\section{RESULTS}

Figure 1 shows the mean rate of responding for all subjects under each deferment interval under both the signaled and unsignaled procedures. For all animals the rate of responding was higher under the unsignaled than under the signaled condition. As the deferment interval increased from 0 to $5.0 \mathrm{sec}$, response rates decreased. The resultant gradients obtained under both conditions reflect the effect of the response-ESB interval.

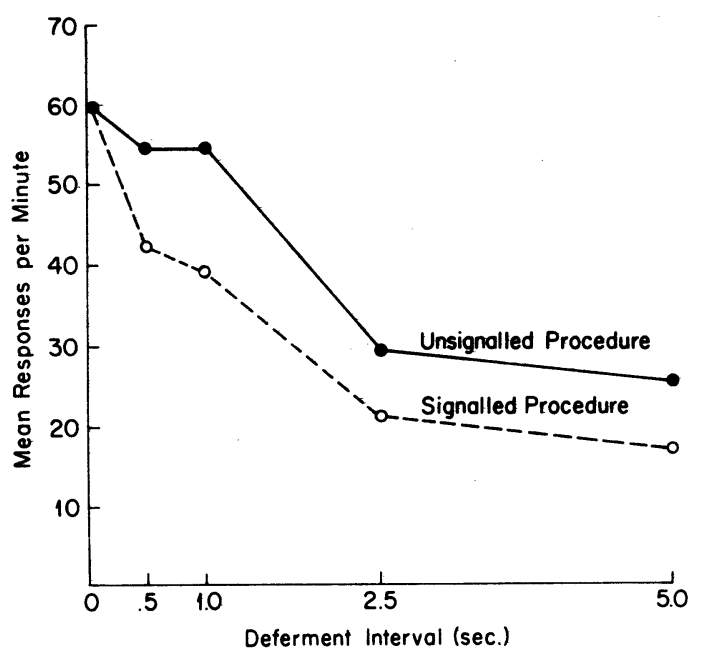

Figure 1. Mean response rates under signaled (dashed line) and unsignaled (solid line) procedures. 
The deferment gradient is not as steep as that reported by Hurwitz and James (1970). Previous data showed that following deferment intervals of 0.5 and $1.0 \mathrm{sec}$, the response rate declined more than $50 \%$ from the baseline obtained under immediate reinforcement ( 0 deferment). This difference may be due to the use of a different leverpressing apparatus or to the use of different stimulation equipment.

From Figure 1 the overall effect of the signal appears amazingly consistent for the four deferment intervals tested. However, as Table 1 shows, the response rates varied greatly with the subjects under each deferment interval. In only two instances (.5 deferment for Subject F2 and 1.0 deferment for Subject F8) did the higher response rate occur under the signaled deferment. An analysis of variance on the rate of response data showed that decline in rate as a function of the increase in the deferment interval was highly significant $[F(3,32)=$ $13.60, \mathrm{p}<.0001]$. The difference between the signaled and unsignaled conditions was also significant $[F(1,32)=$ $8.12, \mathrm{p}<.007$ ], despite some between-subjects variance and a reversal of trend under the two instances cited above.

A similar analysis of the mean reinforcements received (Table 2) yielded significant effects attributable to the deferment intervals $[F(3,32)=146.5, p<.0001]$ and a significant effect attributable to the availability of a signal during the deferment interval $[F(1,32)=$

Table 1

Mean Response Rate Under Signaled (S) and Unsignaled (US) Deferment Intervals

\begin{tabular}{|c|c|c|c|c|c|c|c|c|}
\hline \multirow[b]{3}{*}{ Subject } & \multicolumn{8}{|c|}{ Deferment Interval } \\
\hline & \multicolumn{2}{|c|}{.5} & \multicolumn{2}{|c|}{1.0} & \multicolumn{2}{|c|}{2.5} & \multicolumn{2}{|c|}{5.0} \\
\hline & 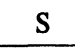 & US & $S$ & US & $S$ & US & $S$ & US \\
\hline $\begin{array}{l}\text { E39 } \\
\text { F2 } \\
\text { F8 } \\
\text { F15 } \\
\text { F17 }\end{array}$ & $\begin{array}{l}33.3 \\
50.5 \\
59.6 \\
31.7 \\
36.3\end{array}$ & $\begin{array}{l}41.1 \\
46.8 \\
66.6 \\
52.2 \\
65.3\end{array}$ & $\begin{array}{l}29.9 \\
42.7 \\
71.5 \\
17.2 \\
34.7\end{array}$ & $\begin{array}{l}39.7 \\
54.9 \\
63.6 \\
42.1 \\
71.2\end{array}$ & $\begin{array}{r}21.2 \\
21.7 \\
39.0 \\
15.7 \\
9.4\end{array}$ & $\begin{array}{l}27.2 \\
26.0 \\
40.0 \\
28.4 \\
23.3\end{array}$ & $\begin{array}{r}16.3 \\
18.1 \\
31.0 \\
12.1 \\
8.7\end{array}$ & $\begin{array}{l}22.0 \\
27.0 \\
38.4 \\
21.6 \\
20.6\end{array}$ \\
\hline Mean & 42.2 & 54.4 & 39.2 & 54.3 & 21.5 & 28.8 & 17.2 & 25.9 \\
\hline
\end{tabular}

Table 2

Mean Reinforcements Received Under Signaled (S) and Unsignaled (US) Deferment Intervals

\begin{tabular}{|c|c|c|c|c|c|c|c|c|}
\hline \multirow[b]{3}{*}{ Subject } & \multicolumn{8}{|c|}{ Deferment Interval } \\
\hline & \multicolumn{2}{|c|}{.5} & \multicolumn{2}{|c|}{1.0} & \multicolumn{2}{|c|}{2.5} & \multicolumn{2}{|c|}{5.0} \\
\hline & $\mathrm{S}$ & US & $S$ & US & $S$ & US & $\mathrm{S}$ & US \\
\hline $\begin{array}{l}\text { E39 } \\
\text { F2 } \\
\text { F8 } \\
\text { F15 } \\
\text { F17 }\end{array}$ & $\begin{array}{l}26.5 \\
28.7 \\
29.8 \\
21.3 \\
24.6\end{array}$ & $\begin{array}{l}29.3 \\
26.7 \\
32.5 \\
30.0 \\
37.3\end{array}$ & $\begin{array}{l}18.7 \\
16.6 \\
23.8 \\
11.6 \\
16.4\end{array}$ & $\begin{array}{l}22.3 \\
23.2 \\
23.2 \\
19.1 \\
26.4\end{array}$ & $\begin{array}{r}10.0 \\
5.5 \\
8.8 \\
7.2 \\
4.4\end{array}$ & $\begin{array}{r}11.5 \\
7.4 \\
9.8 \\
8.4 \\
9.8\end{array}$ & $\begin{array}{l}6.0 \\
4.4 \\
6.3 \\
4.1 \\
3.4\end{array}$ & $\begin{array}{l}6.6 \\
4.9 \\
6.8 \\
5.3 \\
5.4\end{array}$ \\
\hline Mean & 26.2 & 31.2 & 17.4 & 22.8 & 7.2 & 9.4 & 4.8 & 5.8 \\
\hline
\end{tabular}

14.4, $p=.034]$. The trend was for fewer ESB reinforcements to be delivered under the signaled condition.

\section{DISCUSSION}

The results have shown that, when a signal was presented during the deferment interval, the rate of leverpressing tended to be lower than when the deferment was unsignaled. The unsignaled results replicated, in essentials, previously reported data by the present writers (Hurwitz \& James, 1970)-namely, that the rate of response undergoes a massive deterioration with relatively small intervals between the response and the responsecontingent delivery of ESB. The data furthermore showed a highly significant difference in the number of ESBs obtained under the signaling condition: The use of a signal to mark the deferment interval resulted in consistently fewer deliveries of ESB. This result is clearly at odds with the prediction that a signal enhances the presumptive reinforcing effect of ESB upon responses, that it has response-preserving functions or facilitates behaviors that eventually produce ESB. It has been suggested that the signal acts to inform the subject of the availability of the ESB and that this might lead to a reduction in response rate during presentation of the signal, that is, the subject is waiting for ESB without making additional leverpressing responses. But this interpretation is incompatible with the present results, which showed not only a reduction in the rate of response but also a reduction in the number of ESBs received by the subject. One would not expect the subject to drop the frequency of reinforcements, if indeed ESB qualifies as a reinforcer in the traditional sense.

One should also consider the possibility that the signal used was disruptive without making the stronger assumption that it had aversive properties. An aversive stimulus would be one which the subject would actively avoid or escape from and in whose presence appetitively motivated responses would be suppressed. There is no evidence in the literature or from the authors' work that the kind of stimulus source used had such properties. The signal, it will be recalled, was audiotactile, which yielded $85 \mathrm{~dB}$ as measured in the experimental chamber against an ambient noise level of $75 \mathrm{~dB}$.

The signal's disruptive properties could be related to two other factors apart from those that would define it as an aversive stimulus. First, it must be demonstrated that the signaling stimulus controls responses which could compete with and interfere with responses related to the signal function of the stimulus. Later research by James (Note 1) has demonstrated that, in the case of pigeons and conventional reinforcers, deferred reinforcement frequently results in superstitious behavior during unsignaled deferment intervals. Such behaviors compete or interfere with the desired operant response of keypecking, resulting in lower rates of responding and, consequently, in lower frequency of reinforcements. It is suspected that introduction of a signal would bring such superstitions under stimulus control and thereby lower the rate of responding during signaled deferment intervals.

Second, the strength of the signal relative to the strength of the reinforcer must be substantial. The second qualification contains some degree of circularity, since strength in this sense is not a physical property but behavioral. Previously Hurwitz and James (1970) showed that ESB is, at best, a weak reinforcer which has tenuous relations to the responses under deferment intervals. It therefore seems plausible to assume that the results of the present experiment are yet a further demonstration of the thesis that ESB has weak response-reinforcing effects when it is deferred for even short intervals. Indirectly it supports the notion that the signal has some disruptive properties of its own that at times overshadow the effects of ESB. 


\section{REFERENCE NOTE}

1. James, R. E. Concurrent performance: Preference under deferment and fixed-interval schedules. Paper presented at the American Psychological Association, August 1977.

\section{REFERENCES}

CANTOR, M. B. Signaled reinforcing brain stimulation facilitates operant behavior under schedules of intermittent reinforcement. Science, 1971, 174, 610-613.

Cantor, M. B., \& LoLordo, V. M. Rats prefer signaled reinforcing brain stimulation to unsignaled ESB. Journal of Comparative and Physiological Psychology, 1970, 71, 183-191.
Cooper, B. R., Morse, D. L., Potts, D. J., \& Black, W. C. A simplified and inexpensive swivel for electrical stimulation. Physiology and Behavior, 1969, 4, 117-118.

HuRwitz, H. M. B., \& JAMEs, R. E. Deferment of intracranial reinforcement: Incentive power of ICS. Physiology and Behavior, 1970, 5, 1309-1312.

RenNer, K. E. Delay of reinforcement: A historical review. Psychological Bulletin, 1964, 61, 341-361.

(Received for publication March 31, 1978.) 